\title{
FEIÇÕES BIOLÓGICAS EM PALEOSSOLOS DA FORMAÇÃo MARÍLIA EM MINAS GERAIS.
}

\author{
Diego Luciano do Nascimento ${ }^{(a)}$, Francisco Sérgio Bernardes Ladeira ${ }^{(b)}$ Alessandro Batezelli ${ }^{(c)}$ \\ (a) Instituto de Geociências, Universidade Estadual de Campinas - Unicamp, diego.nascimento@ige.unicamp.br \\ (b) Instituto de Geociências, Universidade Estadual de Campinas - Unicamp, fsbladeira@ige.unicamp.br \\ (c) Instituto de Geociências, Universidade Estadual de Campinas - Unicamp, abatezelli@ige.unicamp.br
}

\section{EIXO: SOLOS E PAISAGENS}

\begin{abstract}
Resumo
Os paleossolos são importantes indicadores paleoambientais, pois preservam evidências dos fatores e processos que atuaram durante sua evolução. Dentre estes fatores, a atividade biológica se mostra de grande importância, principalmente em paleossolos de ambientes semiáridos, pois atuam na precipitação e dissolução de carbonato de cálcio, aumentando seu potencial de preservação destes perfis de alteração no registro geológico. Neste trabalho realizamos a caracterização macro e micromorfológica dos paleossolos da Formação Marília em Minas Gerais, atentando para descrição das feiçoes biogênicas preservadas. Os resultados obtidos indicaram que o papel das raízes e de microrganismos, como fungos e bactérias foi fundamental para evolução de horizontes carbonáticos dos paleossolos, através da precipitação de cimento micrítico no espaço poroso do solo, principalmente nas proximidades dos rizólitos de suas paleorizosferas, processo este similar ao desenvolvimento de horizontes carbonáticos em solos atuais.
\end{abstract}

Palavras chave: Rizólitos, Calcretes, Bacia Bauru, Paleopedologia, Micromorfologia

\section{Introdução}

Os paleossolos carbonáticos (calcretes) da Formação Marília, da Bacia Sedimentar Bauru são importantes registros da dinâmica paleoambiental durante o Cretáceo Superior, atestando as condições paleoclimáticas semiáridas atuantes em um sistema aluvial distributivo (Suguio, 1973; Barcelos, 1984; Pereira et al. 2015; Batezelli, 2015). Além das condições paleoclimáticas, os paleossolos fornecem informações a respeito da atividade biológica atuante no desenvolvimento dos solos, pois conservam feições macro e micromorfológicas ligadas a atividade da flora e da fauna.

Dentre estas feições, os rizólitos são estruturas organo-sedimentares produzidas pela atividade de raízes em vida, bem como após sua morte, podendo preservar a arquitetura da antiga raiz e as características da rizosfera (Klappa, 1980; Kraus e Hasiotis, 2006), indicando a exposição subaérea do material de origem do solo e sua colonização por plantas. O sistema radicular é um dos principais componentes biológicos do solo, atuando no seu desenvolvimento e quando preservado é fonte de informações paleoambientais, como a organização, distribuição e características da antiga cobertura vegetal. 
A influência biológica no desenvolvimento dos calcretes é tema central dos estudos relacionados a paleopedologia, pois acumulação de carbonato de cálcio mediado pelas raízes é notável, sendo possível sua descrição e caracterização na escala macromorfológica em campo, bem como em laboratório, por meio da descrição micromorfológica (Klappa, 1980; Wright et al., 1988; Alonso-Zarza, 1999; Kosir, 2004).

Desta forma o objetivo do presente trabalho é a caracterização macro e micromorfológica dos rizólitos das microfábricas biogênicas preservadas nos paleossolos da Formação Marília, destacando sua importância desenvolvimento e acumulação de $\mathrm{CaCO}_{3}$ nestes paleossolos cretácicos.

\section{Materiais e Métodos}

A área de estudo está localizada ao longo da Rodovia Juscelino Kubitschek de Oliveira - BR 364, próximo ao município Gurinhatã - MG, pertencente à mesorregião do Triangulo Mineiro (Fig. 1A). Esta região foi escolhida, pois conta com boas exposições da Formação Marília ao longo de rodovias, que possibilita sua descrição da base ao topo e a escolha das melhores seções.

Os paleossolos descritos neste trabalho estão inseridos entre os litotipos da Formação Marília que data do Maastrichtiano (Dias-Britto et al. 2001). Seus litotipos são constituídos predominantemente por arenitos e conglomerados matriz suportados, depósitos arenoargilosos subordinados e paleossolos ricos em CaCO3. As arquiteturas deposicionais preservadas são de canais fluviais, barras arenosas lenticulares e depósitos de planície de inundação e overbank (Fig. 1 B,C), compondo complexos de canais amalgamados, intercalados por paleossolos.

Seu ambiente deposicional é caracterizado por um sistema deposicional aluvial em ambiente semiárido, dominado por rios entrelaçados de baixa sinuosidade com carga mista que fluíam de Norte/Nordeste para Sul/Sudoeste a partir de um alto estrutural denominado Alto Paranaíba (SAP) (Batezelli, 2015). A dinâmica semiárida na área é atestada pela presença de dunas eólicas que retrabalharam os depósitos fluviais, ventifactos, bem como grande quantidade de calcretes pedogenéticos e minerais de argila do grupo das illitas e paligorskitas/sepiolitas (Suguio e Barcellos, 1983).

Os paleossolos foram descritos em campo de acordo com as recomendações do Soil Survey Staff (1999) para caracterização macromorfológica e identificação de horizontes. As estruturas pedológicas 
foram descritas quanto ao tamanho, forma, dureza e grau de desenvolvimento, além das características pedológicas como, nódulos, mosqueamentos, cimentação e bioturbações.

A descrição micromorfológica de laminas delgadas seguiram os procedimentos indicados por Brewer (1976), para apreender da organização do esqueleto, plasma, poros e feições pedológicas (cutãs, glébulas e cristalárias, por exemplo) sempre com as amostras orientadas da base para o topo. Complementar à análise micromorfológica, foi utilizado o Microscópio Eletrônico de Varredura (MEV) para identificação e caracterização de feições associada a recristalização de carbonato e suas relações com a atividade biológica.

\section{Resultados}

\subsection{Paleossolos}

\subsubsection{Paleossolos bem desenvolvidos (Bk e Btk)}

Estes paleossolos apresentam horizontes Bk e Btk muito espessos podendo atingir até 2 metros de altura ou pelo empilhamento de diferentes paleossolos bem desenvolvidos ricos em carbonato que variam de 1,5 m a 1,8m, separados ora por depósitos ou por paleossolos pouco desenvolvidos (Fig. 2 A), caracterizando pedocomplexos (Catt, 1998). A sequência comum destes paleossolos é composta pelos horizontes Bk-C1C2/ou Btk-C1-C2, sendo que os horizontes A nunca estão preservados.

Apresentam estruturas em blocos médios a grandes (Fig. 2B), moderados e duros devido a calcretização. A presença de nódulos carbonáticos de cor branca $(\mathrm{N} / 8)$, milimétricos $(4 \mathrm{~mm})$ a centimétricos $(5 \mathrm{~cm})$ de diâmetro variam de comum a abundante em todo o perfil.

\subsubsection{Paleossolos pouco desenvolvidos ( $\mathrm{C}$ e $\mathbf{C k})$}

Estes paleossolos são predominantemente constituídos por horizontes $\mathrm{C}$ e $\mathrm{Ck}$, com espessuras entre 0,5 m a 2, 5 metro, ora pouco bioturbados ou intensamente bioturbados e maciços (Fig. 2C). Representam sucessões de horizontes $\mathrm{Ck}-\mathrm{C} 1-\mathrm{C} 2$ ou Ck-C empilhado, truncados por depósitos conglomeráticos. 

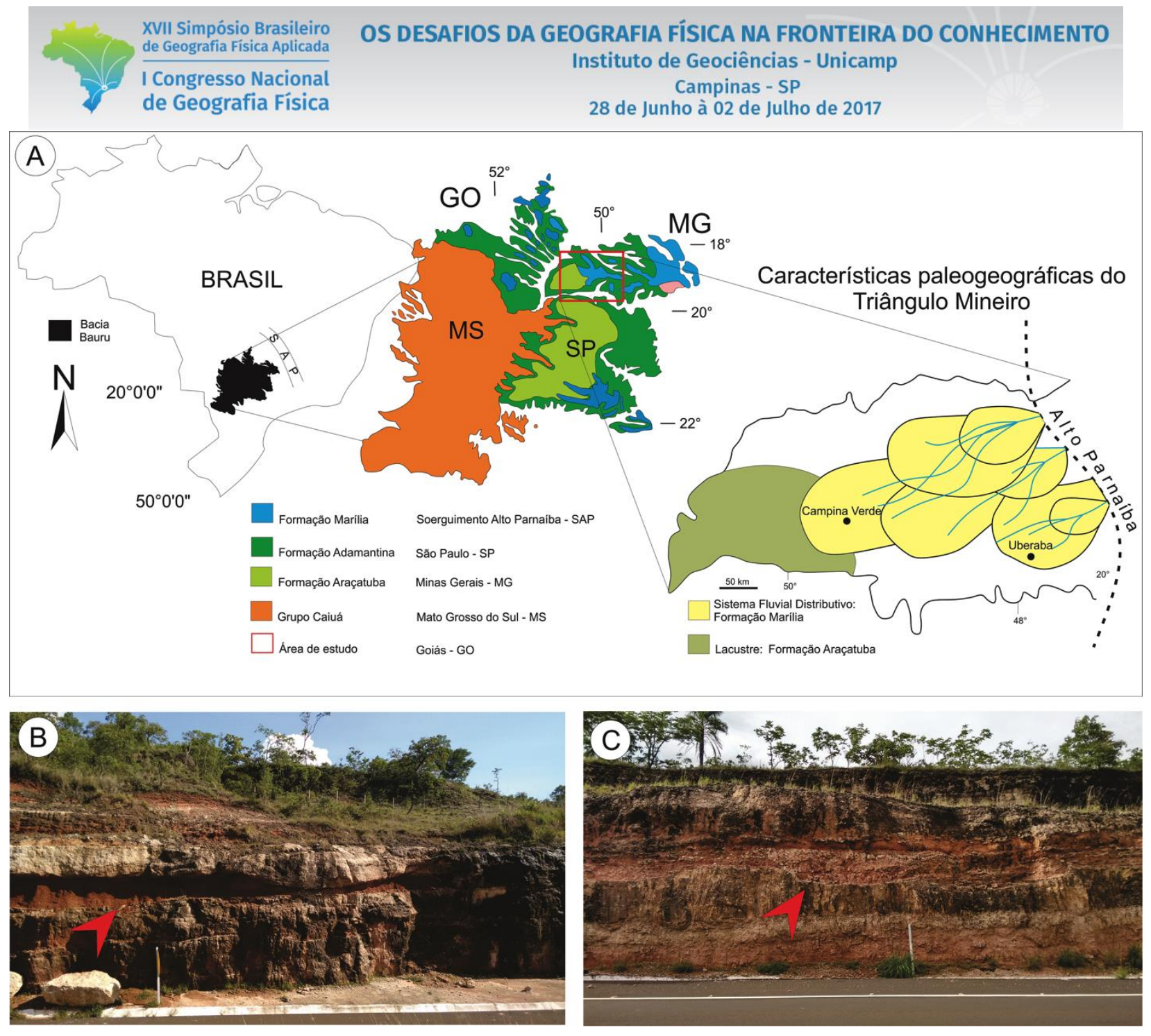

Figura 1: Características gerais da área objeto de estudo. A) Localização da área de estudo e suas características paleogeográficas durante o Cretáceo Superior. B) Depósitos finos associados a planícies de inundação (seta). C) Paleocanal erodindo paleossolos carbonático (seta).

Sua coloração é cinzento-claro (10R7/1) e branco-rosado (5YR8/2), reativos ao $\mathrm{HCl} 10 \%$. Sua textura é arenoconglomerática. Os nódulos de carbonato são comuns a abundantes, variam de $4 \mathrm{~mm}$ a $3 \mathrm{~cm}$ de diâmetro (Fig. 2D). As bioturbações são comuns, preenchidas pelo mesmo material que constitui os paleossolos (Fig. 2E). 

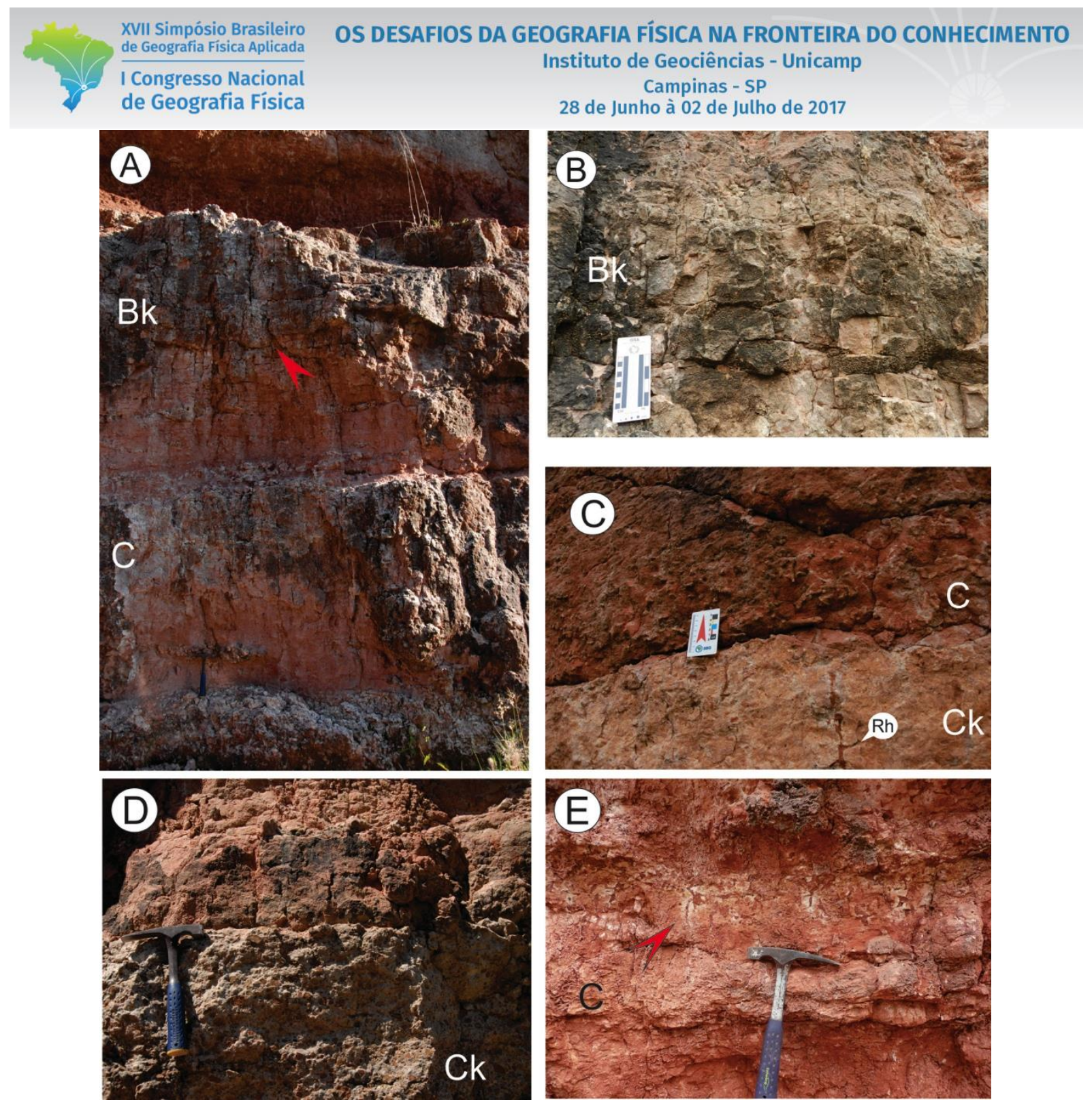

Figura 2: Paleossolos descritos. A) Perfil de paleossolos carbonáticos bem desenvolvido. B) Horizonte Bk com estruturas em blocos. C) Paleossolos pouco desenvolvidos empilhados ( $\mathrm{C} \mathrm{e} \mathrm{Ck).} \mathrm{Rh}$ - Rizólito. D) Horizonte Ck rico em nódulos carbonáticos. E) Horizonte C com rizohalos e feições de depleção de Fe.

\subsection{Rizólitos}

\subsubsection{Rizohalos}

Feições de depleção de Fe e Mn em tons esverdeados e cinzas (Fig. 3A,B), com ramificações verticais e laterais, com diâmetros entre 2 e $5 \mathrm{~mm}$ e comprimento entre 10 e $30 \mathrm{~cm}$ são comuns. As ramificações finas são predominantemente horizontais e partem das ramificações secundárias e primárias, não reativas ao $\mathrm{HCl} 10 \%$. Em algumas ocorrências apresentam o material da antiga raiz ainda visível a olho nu. 


\subsubsection{Moldes de raízes}

Estruturas tubulares verticais, com ramificações laterais horizontais que afunilam ao longo de seu comprimento estão presentes. Seu diâmetro varia de 0,3 a $1 \mathrm{~cm}$ e comprimento de 0,50 a 2 metros desde o topo até a base do perfil (Fig. 3C,D).

\subsubsection{Rizotúbulos}

Estruturas tubulares com padrão de túneis entrelaçados, intensamente ramificados, que variam de 0,5 a 2 $\mathrm{cm}$ de espessura nos tubos individuais, com até $20 \mathrm{~cm}$ de comprimento, tornam-se mais espessas nas porções ramificadas, apresentando padrão dicotômico e se desenvolvendo predominantemente na horizontal (Fig. 3E,F)

\section{Microfábricas biogênicas}

\subsection{Estrutura alveolar-septal}

Estas estruturas são compostas por lâminas micriticas entrelaçadas que preenchem o espaço poroso e revestem a fração grossa do solo, podendo conter impurezas, como argilas, óxidos e matéria orgânica conferindo tonalidades marrons ao material carbonático (Fig. 4A).

\subsection{Calcita citomórfica}

A calcita citomórfica (Fig. 4B) ocorre em resposta aos processos de calcificação e descalcificação associadas à cimentação intra e extracelular das raízes. Esta feição é constituída por cristais de calcita esparítica equigranulares, preenchendo canais, sendo comum nos solos de ambientes semiáridos (Durand et al., 2010). Sua presença na forma de cristais isolados nos paleossolos se dá em reposta aos processos de pedoturbação que a incorpora na matriz do solo.

\subsection{Esferulitos}

Associados à atividade de cianobactérias nos solos, os esferulitos apresentam-se com aspecto fibro-radial composto por múltiplos cristais de calcita (Fig. 4C), compondo um agregado cristalino esférico ou oval, comuns em crostas laminares.

\subsection{Esporos e filamentos fungais calcificados}

Esporos e filamentos de fungos calcificados são feições comuns em calcretes Quaternários, ocorrendo na forma de fibras lisas similares aos micélios ou hifas fúngicas, ligadas a esporos esféricos (Fig. 4D) cimentados por oxalato de cálcio e associados a matriz micrítica (Durand et al. 2010). 

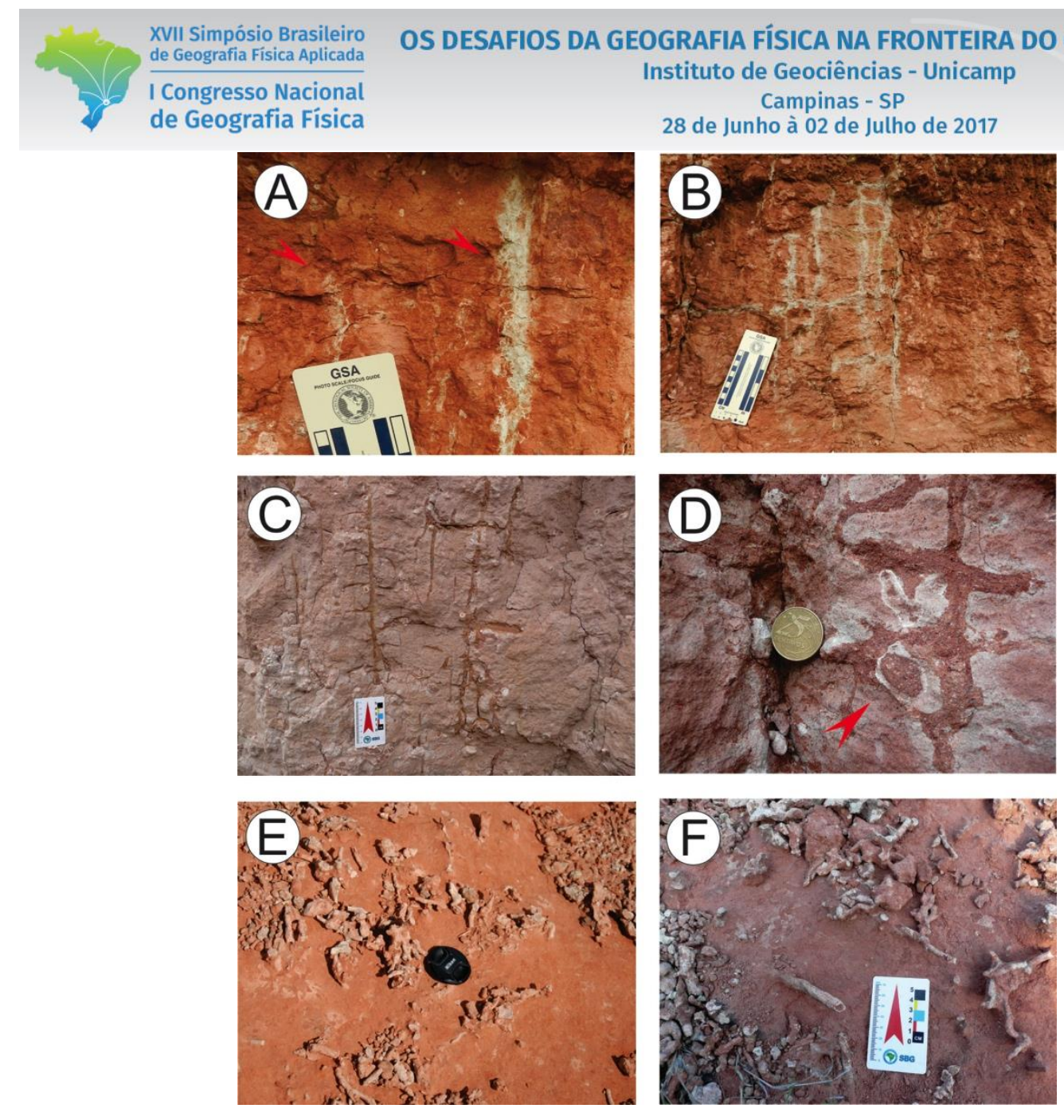

Figura 3: Rizólitos presentes nos paleossolos descritos. A,B) Rizohalos. C,D) moldes de raízes preenchidos por material arenoso. Observa-se a rizoconcreção (seta) carbonática associada ao rizólito. E,F) Rizotúbulos cimentados por $\mathrm{CaCO}_{3}$. 

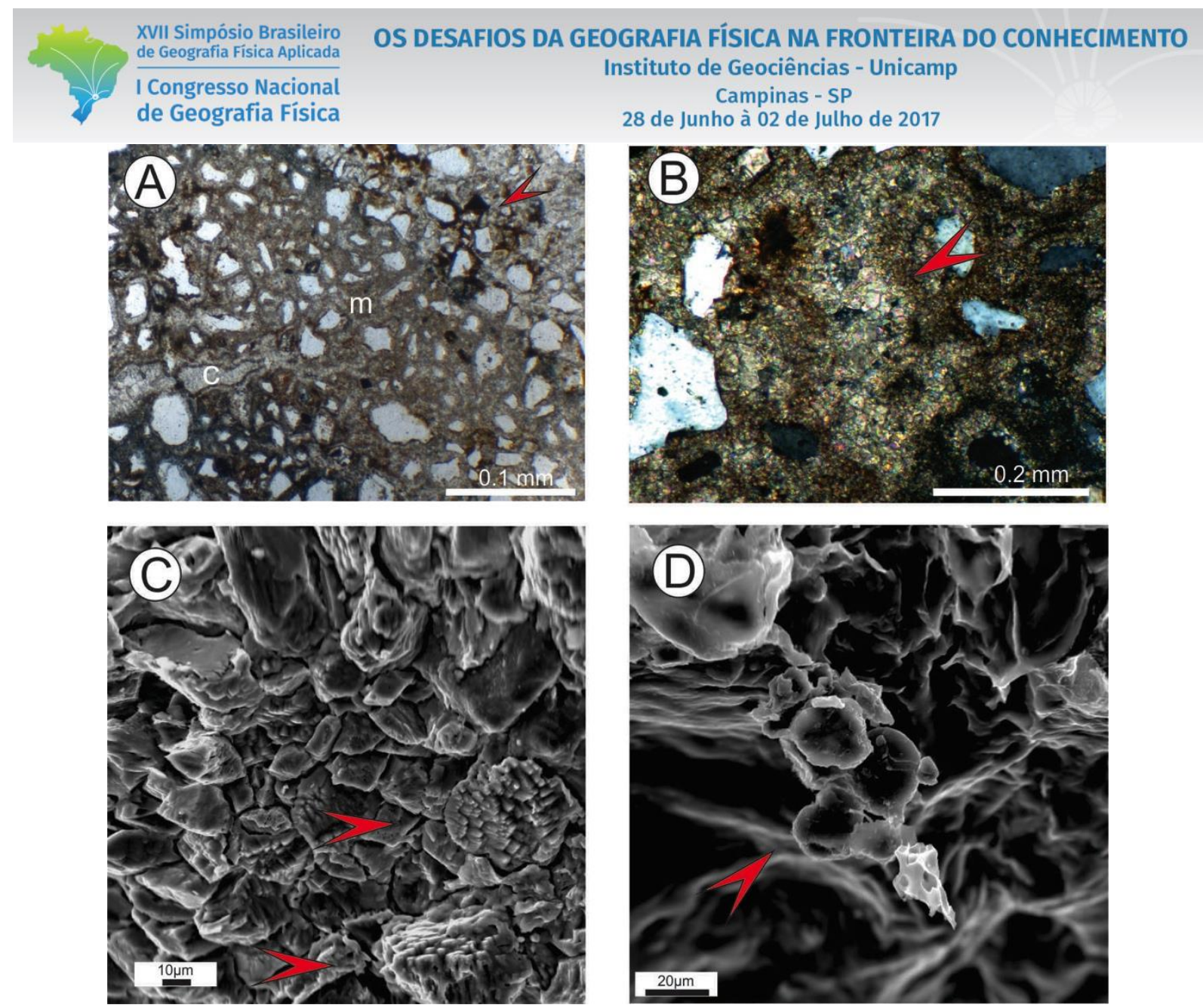

Figura 4: Micro e submicrofeições biogênicas. A) Feição alveolar - septal resultante da atividade biológica das raízes. Note as laminações micríticas (m) próximas a calcita citomórfica (c) indicando a influência radicular na precipitação de carbonato, bem como na mobilização de óxidos (seta). B) Calcita citomórfica. Os cristais granulares são indicados pela seta. As porções escuras estão associados a óxidos de Fe e Mn. C) Imagem dos esferulitos (setas) obtidas pelo MEV. Observa-se o padrão composto fibroso composto por cristais aglomerados. D) Imagem dos esporos e filamentos fúngicos (seta) obtidas pelo MEV.

\section{Discussão}

Os resultados obtidos com a caracterização dos paleossolos e os rizólitos indicam diferentes condições ambientais de desenvolvimento dos solos, no que diz respeito às condições paleohidrológicas, bem como a importância das raízes para evolução dos solos carbonáticos. O microclima (condições de temperatura e umidade nos poros) é resultado dos condicionantes de evolução dos solos, diretamente relacionados a escala local da topografia, para os solos desenvolvidos em planícies aluviais, a umidade em função da topografia e proximidade com lençol freático faz com que os solos dependam muito mais das condições locais do que dos fatores atmosféricos (Retallack, 2001). 
Os rizohalos exemplificam esta relação, pois são evidências de processos redoximórficos associados à redução do Fe nas proximidades das raízes devido à degradação da matéria orgânica em solos saturados, como menor quantidadede $\mathrm{O}_{2}$ (Vepraskas, 1994; Kraus e Hasiotis, 2006). Isto indica que apesar do clima semiárido, os solos desenvolvidos nas planícies de inundação desenvolveram feições de gleização.

No caso dos moldes de raízes que apresentam comprimento de até 2 metros a situação muda, pois eles nos indicam condições de boa drenagem do solo e lençol freático que rebaixado. Isto, somado aos rizotúbulos cimentados por $\mathrm{CaCO}_{3}$ reforçam as condições paleoclimáticas semiáridas regionais que configuram as microfeições biogênicas.

As estruturas alveolares (Fig. 3A) estão associadas à atividade das raízes que viabilizam a precipitação de carbonato de cálcio nos paleossolos. Os filamentos e envelopes micríticos indicam a constante precipitação de $\mathrm{CaCO}_{3}$ na zona vadosa do solo próxima da rizosfera, caracterizando o processo de calcificação extracelular do tipo beta (Wright et al. 1995), comuns e em calcretes laminares. Isto ocorre, pois a atividade biológica altera as concentrações de $\mathrm{CO}_{2}$ no solo, afetando diretamente a dissolução e a precipitação do carbonato de cálcio (Cerling, 1984)

Os esferulitos (Fig. 4C) são feições característicos dos calcretes rizogênicos (Wright et a., 1995) e ocorrem na interface calcrete-atmosfera ou próximos ao topo dos paleossolos, pois a exposição a luz favorece a atividade de cianobactérias em ambientes semiáridos (Verrecchia et al., 1995). Além das cianobactérias, as observações realizadas no microscópio eletrônico de varredura (MEV) indicaram a presença de esporos e filamentos fúngicos calcificados (Fig. 4D) destacando também o papel de fungos no desenvolvimento da matriz micrítica que preenchem o espaço poroso e revestem os grãos dos calcretes. Apesar de evidências de células de raízes calcificadas, como a calcita citomórfica e a cimentação dos rizólitos são, em sua grande maioria, extracelulares, similares a calcretes laminares Quaternárias (Wright et al. 1995; Alonso-Zarza e Jones, 2007).

\section{Conclusões}

Os resultados obtidos com caracterização macro e micromorfológica de paleossolos e rizólitos indicam que a atividade das raízes e dos microrganismos, com fungos e cianobactérias foram de grande importância para o desenvolvimento dos paleossolos carbonáticos da Formação Marília, pois atuaram na precipitação e redistribuição de $\mathrm{CaCO}_{3}$ evidenciado pelas estruturas alveolares-septais compostas por micrita de origem pedogenética. Os diferentes modos de preservação dos rizólitos se deram em resposta às condições paleohidrológicas dos paleossolos durante seu desenvolvimento, pois apenas os paleossolos bem drenados preservaram moldes de raízes e rizotúbulos cimentados por carbonato, indicando que pelo menos parte do ano ocorria um déficit hídrico. 


\section{Bibliografia}

ALONSO-ZARZA, A.M. Initial stages of laminar calcrete formation by roots: examples from the Neogene of central Spain. Sedimentary Geology 126, 177-191. 1991.

ALONSO-ZARZA, A. M.; JONES, B. Root calcrete formation on Quaternary karstic surfaces of Grand Cayman. Geologica Acta, 5(1), 77-88. 2007.

BARCELOS, J.H. Reconstrução Paleogeográfica da Sedimentação do Grupo Bauru Baseada na sua Redefinição Estratigráfica Parcial em Território Paulista e no Estudo Preliminar Fora do Estado de São Paulo. 1984. 190 f. Tese (Livre Docência) - Instituto de Geociências e Ciências Exatas, Universidade Estadual Paulista, Rio Claro.

BATEZELLI, A. Continental systems tracts of the Brazilian Cretaceous Bauru Basin and their relationship with the tectonic and climatic evolution of South America. Basin Research 27, 1-25. 2015.

CERLING, T.E., The stable isotopic composition of modern soil carbonate and its relationship to climate. Earth Planetary. Science. Letters., 71, 229-240, 1984.

BREWER, R. Fabric and Mineral Analysis of Soils. New York, Robert E. Krieger Publishing Company, 1976. DIAS-BRITTO, D.; MUSACCHIO, E.A.; CASTRO, J.C.; MARANHÃO, M.S.A.S.; SUÁREZ, J.M.; RODRIGUES, R. Grupo Bauru: uma unidade continental Cretácea no Brasil - concepções baseadas em dados micropaleontológicos, isotópicos e estratigráficos. Revue Paléobiologic, Genève 20, 245-304. 2001.

DURAND, N.; MONGER, H.C.; CANTI, M.G. Calcium carbonate features. In: STOOPS, G.; MARCELINO, V.; MEES, F. (eds.), Interpretation of Micromorphological Features of Soils and Regoliths. Elsevier, Amsterdam, 2010. p. 149-194.

KLAPPA, C.F. Rhizoliths in terrestrial carbonates: classification, recognition, genesis, and significance. Sedimentology 26, 613-629. 1980.

KOSIR, A. Microcodium revisited: root calcification product of terrestrial plants on carbonate-rich substrates. Journal of Sedimentary Research 74, 845-857. 2004.

KRAUS, M.J.; HASIOTIS, S.T. Significance of different modes of rhizolith preservation to interpreting paleoenvironmental and paleohydrologic settings: examples from Paleogene paleosols, Bighorn Basin, Wyoming, U.S.A. Journal of Sedimentary Research 76, 633-646. 2006.

PEREIRA, C.T.; BATEZELLI, A.; LADEIRA, F.S.B. Paleoprecipitation changes based on paleosols profiles of the Marília Formation (Upper Cretaceous) in the eastern portion of the Bauru Basin in Southeastern Brazil. Geociências 34, 238-257. 2015.

RETALLACK, G.J. Soils of the Past - An introdution to paleopedology. London: Unwin Hyman. 2001.

SUGUIO, K. Formação Bauru: calcários e sedimentos detríticos associados. São Paulo, 2v. 1973. Tese (Livre Docência) - Instituto de Geociências, Universidade de São Paulo.

SUGUIO, K.; BARCELOS, J.H. Calcretes of the Bauru Group (Cretaceous) Brazil: petrology and Geological significance. Boletim IG (São Paulo) 14, 31-47. 1983.

VEPRASKAS, M.J.; WILDING, L.P.; DREES, L.R. Aquic conditions for soil taxonomy: concepts, soil morphology, and micromorphology. In: RINGROSE-VOASE, A.J.; HUMPHREYS, G.S. (eds.), Soil Micromorphology: Studies in Management and Genesis. Developments in Soil Science, Volume 22. Elsevier, Amsterdam, 1994. p. 117-131. 
VERRECCHIA, E.P.; FREYTET, P.; VERRECCHIA, K.E.; DUMONT, J.L. Spherulites in calcrete laminar crusts: biogenic $\mathrm{CaCO3}$, precipitation as a major contributor to crust formation. Journal of Sedimentary Research 65, 690-700. 1995.

WRIGHT, V.P.; PLATT, N.H.; WIMBLEDON, W.A. Biogenic laminar calcretes: evidence of calcified root-mat horizons in paleosols. Sedimentology 35, 603-620. 1988.

WRIGHT, V.P.; PLATT, N.H.; MARRIOTT, S.B.; BECK, V.H. Classification of rhizogenic (root-formed) calcretes. with examples from the Upper Jurassic-Lower Cretaceous of Spain and Upper Cretaceous of southern France. Sedimentary Geology 100, 143-158. 1995. 